\title{
Aspectos ultra-estruturais dos canais secretores em órgãos vegetativos e reprodutivos de Anacardiaceae ${ }^{1}$
}

\author{
Ana Paula Stechhahn Lacchia ${ }^{2,4}$ e Sandra Maria Carmello Guerreiro ${ }^{3}$
}

\author{
Recebido em 27/09/2007. Aceito em 11/08/2008
}

\begin{abstract}
RESUMO - (Aspectos ultra-estruturais dos canais secretores em órgãos vegetativos e reprodutivos de Anacardiaceae). Neste trabalho foi estudado o desenvolvimento e a ultra-estrutura dos canais do floema dos ápices vegetativos de Spondias dulcis G. Forst., a ultra-estrutura dos canais floemáticos dos ápices vegetativos de Tapirira guinanensis Aubl., bem como, a ultra-estrutura e o desenvolvimento dos canais florais e a ultra-estrutura dos canais do fruto desta mesma espécie Os canais florais e do fruto de Anacardium humile St.Hil. também foram estudados ultra-estruturalmente. Os canais dos ápices vegetativos de $S$. dulcis formam-se de modo esquizolisígeno e os florais de T. guianensis desenvolvem-se, de modo esquizógeno. As células epiteliais dos canais de $S$. dulcis e T. guianensis possuem retículo endoplasmático rugoso, ribossomos livres, plastídios alongados, de diferentes formatos, com presença de inclusões osmiofílicas e dictiossomos com produção de vesículas. Estas organelas estão envolvidas na secreção de um exsudato heterogêneo composto por substâncias hidrofílicas e lipofílicas. As células epiteliais do fruto de $A$. humile apresentam plastídios, em grande quantidade, de forma arredondada com sistema de membranas circular, que estão envolvidos na síntese de substâncias lipofílicas. Os resultados das análises ultra-estruturais das células epiteliais corroboram com os resultados previamente obtidos por estudo histoquímico, através deste estudo, substâncias lipídicas e hidrofílicas foram identificadas nos canais de T. guinanensis e $S$. dulcis e apenas substância lipídicas nos canais de A. humile. Baseado nos aspectos ultraestruturais dos canais secretores de T. guianensis e S. dulcis nós pudemos concluir que os plastídios das células epiteliais dos canais das duas espécies são diferentes, apesar destes secretarem exsudatos de composição semelhante. Um registro novo para a família é a presença de um grande número de plastídios circulares em células epiteliais do fruto de A. humile. O padrão encontrado entre os canais secretores das espécies estudadas é o modo écrino de liberação da secreção.
\end{abstract}

Palavras-chave: Anacardiaceae, canais secretores, desenvolvimento, ultra-estrutura

\begin{abstract}
Ultra-structural aspects of secretory canals in vegetative and reproductive organs of Anacardiaceae). The study assessed phloem canal development and ultra-structure in shoot apices of Spondias dulcis G. Forst., phloematic canal ultra-structure in shoot apices of Tapirira guianensis Aubl., and floral canal ultra-structure and development and fruit canal ultra-structure of the latter specie. The flower and fruit canals of Anacardium humile St.Hil. were also studied ultra-structurally. The canals in shoot apices of S. dulcis show schizo-lysigenous formation and the floral canals of T. guianensis show schizogenous development. Epithelial cells of S. dulcis and T. guianensis canals have rough endoplasmic reticulum, free ribosomes, elongated plastids of several shapes with osmiophilic inclusions and dictyosomes with production of vesicles. Such organelles participate in the secretion of a heterogeneous exudate, which is comprised of hydrophilic and lipophilic substances. The epithelial cells of the fruit of A. humile present elongated plastids with circular membrane system, which are involved in the synthesis of lipophilic substances. The results of the ultra-structural analyses of the epithelial cells corroborate the results previously obtained in a histochemical study. In the histochemical study, lipophilic and hydrophilic substances were identified in the canals of T. guinanensis and $S$. dulcis and only lipophilic substances were identified in the canals of A. humile. Based on the ultrastructural aspects of the secretory canals of T. guianensis and S. dulcis we concluded that the plastids of the epithelial cells of the two species are different although they produce secretion of similar composition. A new record for the family is the presence of a great number of circular plastids in epithelial cells of the fruit of Anacardium humile. The pattern found in the secretory canals of the studied species is the ecrine type of secretion release.
\end{abstract}

Key words: Anacardiaceae, development, secretory canals, ultra-structure

\section{Introdução}

Anacardiaceae está incluída na Ordem Sapindales (APG 2003) sendo composta por 70 gêneros com aproximadamente 600 espécies, principalmente de distribuição pantropical, com poucas de regiões temperadas (Judd et al. 1999). Esta família está dividida em cinco tribos, sendo que no Brasil estão representadas as tribos Anacardiëae, Rhoëae e Spondiadeae (Falcão 1966).

\footnotetext{
Parte da Tese de Doutorado da primeira Autora, Programa de Pós-Graduação em Biologia Vegetal, Universidade Estadual de Campinas

2 Universidade Estadual da Paraíba, Departamento de Biologia, Centro de Ciências Biológicas e da Saúde, Campus Universitário Bodocongó, 8109-790 Campina Grande, PB, Brasil

3 Universidade Estadual de Campinas, Departamento de Botânica, C. Postal 6109, 13083-970 Campinas, SP, Brasil

4 Autor para correspondência: lacchia@ hotmail.com
} 
A peculiaridade anatômica marcante das Anacardiacaeae é a presença de canais/cavidades secretores em órgãos vegetativos e reprodutivos (Metcalfe \& Chalk 1950). Esses canais/cavidades produzem substâncias de uso medicinal, industrial e com efeitos alergênicos (Judd et al.1999).

Os canais dos órgãos vegetativos de Anacardiaceae podem ser encontrados no floema primário, secundário e medula (Metcalfe \& Chalk 1950) e produzem: resina (Morretes 1967; Paula \& Alves 1973; Gibson 1981; Sawidis et al. 2000), goma-resina (Fahn \& Evert 1974; Joel \& Fahn 1980a; b; Nair et al. 1983; Bhatt \& Mohan Ram 1992; Vassilyev 2000), goma (Venkaiah 1992) ou látex (Venning 1948).

Canais estão descritos para os frutos de algumas espécies de Anacardiaceae (Harada 1937; Lozano 1986; von Teichman 1987; 1998; von Teichman \& van Wyk 1991; Pienaar \& von Teichman 1998; Carmello-Guerreiro \& Paoli 2000; Carmello-Guerreiro \& Paoli 2005) e cavidades já foram descritas para frutos de espécies do gênero Anacardium, para frutos de Protorhus namaquensis Spraque e Schinus terebinthifolius Raddi (Paula \& Alves 1973; Paula \& Heringer 1978; von Teichman \& van Wyk 1994; Machado \& CarmelloGuerreiro 2001). Oleorresina (Paula \& Heringer 1978; Paula \& Alves 1973) e resina (Joel \& Fahn 1980c; Lozano 1986) foram caracterizados como produto de secreção dos canais e das cavidades dos frutos de algumas espécies de Anacardiaceae.

Além da descrição dos canais e de suas secreções, a estrutura e a formação dos canais/cavidades em Anacardiaceae foram descritas para algumas espécies (Mc Nair 1918; Harada 1937; Venning 1948; Paula \& Alves 1973; Fahn \& Evert 1974; Joel \& Fahn 1980a; b; c; Nair et al. 1983; Carmello et al. 1995; Machado \& Carmello-Guerreiro 2001). O modo de formação dos canais/cavidades em diferentes espécies e órgãos desta família é amplamente variado (Carmello et al.1995). Os pesquisadores, freqüentemente, sustentam idéias contraditórias a respeito da formação do lume dos canais/cavidades, sendo os modos de formação mais freqüentes o lisígeno, o esquizógeno e o esquizolisígeno (Fahn 1979).

Apesar de existirem trabalhos que relatam à composição da secreção dos canais/cavidades de Anacardiaceae, poucos são aqueles que relacionam a composição da secreção detectada com os aspectos e características ultra-estruturais apresentados pelas células epiteliais (Fahn \& Evert 1974; Joel \& Fahn 1980b; c; Nair et al. 1983; Bhatt \& Ram 1992; Carmello et al. 1995; Machado \& Carmello-Guerreiro 2001). Estudos detalhados incluindo-se ontogênese, estrutura, histoquímica e ultra-estrutura constituem em cada caso, importantes auxílios, pois fornecem dados relacionados com várias transformações bioquímicas e morfo-ultraestruturais das células secretoras (Fahn 1979; Joel \& Fahn 1980a; b; c; Monteiro et al. 1998; Carmello et al. 1995).

Dando prosseguimento aos estudos ultra-estruturais e aos estudos do modo de formação em canais/cavidades secretores em espécies de Anacardiaceae brasileiras (Carmello et al. 1995; Machado \& Carmello-Guerreiro 2001) selecionamos Anacardium humile St.Hil., Spondias dulcis G. Forst. e Tapirira guianensis Aubl. As principais classes de substâncias dos exsudatos, dos canais secretores destas espécies, foram previamente detectadas por testes histoquímicos; compostos lipofílicos e hidrofílicos foram detectados nos canais associados ao floema, dos ápices vegetativos de S. dulcis e nos canais dos ápices vegetativos, flores e frutos de T. guianensis; nos canais do fruto de A. humile foram detectadas apenas substâncias lipofílicas (A.P.S. Lacchia, dados não publicados).

Devido às controvérsias existentes entre os modos de formação dos canais/cavidades secretoras e aos poucos estudos ultra-estruturais dos canais, que relacionam as células epiteliais com suas secreções, nesta família, o objetivo deste trabalho foi caracterizar ultra estruturalmente as células epiteliais dos canais secretores das três espécies de Anacardiaceae brasileiras selecionadas, bem como, identificar o modo de formação dos canais floemáticos dos ápices vegetativos de S. dulcis e dos canais florais de T. guianensis.

\section{Material e métodos}

As espécies estudadas, seus órgãos analisados, bem como, suas localidades de coleta de estão sumarizados na Tab. 1.

Os ápices vegetativos foram obtidos de indivíduos masculinos e femininos de Tapirira guianensis e de indivíduos femininos de Spondias dulcis que continham primórdios foliares medindo até $0,5 \mathrm{~mm}$ e folhas jovens medindo até $0,8 \mathrm{~mm}$ de comprimento. As coletas foram realizadas de setembro/2002 a dezembro/2005. Os materiais testemunha foram herborizados e serão incorporados ao Herbário UEC: A. humile St.Hil.: BRASIL, São Paulo, Botucatu, 14/IX/2004, A. Lacchia 13; Moji Guaçu, 9/IX/2003, A. Lacchia 8; 6/X/2004, A. Lacchia 18, 19, 20, 21; S. dulcis G. Forst.: BRASIL, São Paulo, Campinas, 15/II/2005, A. Lacchia 20, 21, 22; T. guianensis Aubl.: BRASIL, SÃo Paulo, Moji Guaçu, 9/XI/2002, A. Lacchia 4, 1/V/2003, A. Lacchia 7; Pratânia, 3/IX/2002, A. Lacchia 1, 23/IX/2002, A. Lacchia 2, 13/X/2002, A. Lacchia 3, 18/III/2004, A. Lacchia 10. A confirmação da identificação das 
Tabela 1. Espécies de Anacardiaceae estudadas

\begin{tabular}{|c|c|c|}
\hline Espécies estudadas & Órgãos analisados & Localidades de coleta \\
\hline Anacardium humile St.Hil. & $\begin{array}{l}\text { Flores perfeitas } \\
\text { Frutos }\end{array}$ & $\begin{array}{l}\text { Reserva Biológica e Estação Experimental de Moji-Guaçu ( } 22^{\circ} 15^{\prime} 16^{\prime} \text { 'S e } 47^{\circ} 8^{\prime} 12^{\prime \prime} \text { W) } \\
\text { Fazenda Palmeira da Serra em Pratânia }\left(22^{\circ} 48^{\prime} \text { 'S e } 48^{\circ} 40^{\prime} \mathrm{W}\right) \\
\text { Distrito de Rubião Júnior em Botucatu }\left(22^{\circ} 44^{\prime} \mathrm{S} \text { e } 48^{\circ} 34^{\prime} \mathrm{W}\right)\end{array}$ \\
\hline $\begin{array}{l}\text { Spondias dulcis G. Forst. } \\
\text { Tapirira guianensis Aubl. }\end{array}$ & $\begin{array}{l}\text { Ápices vegetativos } \\
\text { Ápices vegetativos } \\
\text { Flores pistiladas } \\
\text { Frutos }\end{array}$ & $\begin{array}{l}\text { Fragmento Florestal na Fazenda Santa Eliza (Campinas-SP) }\left(22^{\circ} 51^{\prime} 20^{\prime \prime} \text { S e } 47^{\circ} 05^{\prime} 34^{\prime \prime} \mathrm{W}\right) \\
\text { Reserva Biológica e Estação Experimental de Moji-Guaçu }\left(22^{\circ} 18^{\prime} \mathrm{S} \text { e } 47^{\circ} 20^{\prime} \mathrm{W}\right) \\
\left.\text { Fazenda Palmeira da Serra em Pratânia ( } 22^{\circ} 48^{\prime} \mathrm{S} \text { e } 48^{\circ} 40^{\prime} \mathrm{W}\right) \\
\left.\text { Distritode Rubião Júnior em Botucatu ( } 22^{\circ} 44^{\prime} \mathrm{S} \text { e } 48^{\circ} 34^{\prime} \mathrm{W}\right)\end{array}$ \\
\hline
\end{tabular}

espécies foi realizada pelo professor Jorge Tamashiro, da Universidade Estadual de Campinas.

Para o estudo da ultra-estrutura do canal secretor, os ápices caulinares de Spondias dulcis e Tapirira guianensis, as flores pistiladas de T. guianensis e as perfeitas de Anacardium humile e os frutos de T. guianensis e A. humile, em vários estádios de desenvolvimento, foram fragmentados e imediatamente fixados em glutaraldeído $2,5 \%$ (tampão fosfato $0,1 \mathrm{M}$ pH 7,2), pós-fixados em tetróxido de ósmio (1\% tampão

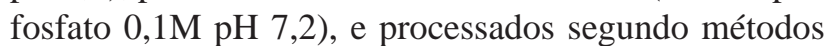
usuais (Roland 1978). As secções ultrafinas foram contrastadas com acetato de uranila (Watson 1958) e citrato de chumbo (Reynolds 1963), recobertas por filme plástico (Formvar) e observadas em microscópio eletrônico de transmissão (Philips E.M. 301).

Para o estudo estrutural do desenvolvimento dos canais secretores, ápices vegetativos de Spondias dulcis foram fixados em FAA por 24 horas (Johansen 1940) e em FNT por 48 horas (Lillie 1965). Após esses períodos, o material foi desidratado em série butílica e incluído em "Paraplast", seccionado transversal e longitudinalmente com 12 a $14 \mu \mathrm{m}$ de espessura em micrótomo rotativo Microm HM340E. As secções foram coradas com safranina e azul de astra (Gerlach 1984) e montadas em resina sintética. No material fixado em FNT foi aplicado o reagente preto de Sudão B (Pearse 1985).

\section{Resultados}

Nas espécies selecionadas para nosso estudo pudemos verificar que as estruturas secretoras são em todas elas e em todos os órgãos, canais, por apresentarem lume alongado em secções longitudinais.

Ápices vegetativos (Spondias dulcis e Tapirira guianensis) - Em S. dulcis e T. guianensis os canais secretores foram encontrados associados ao floema (Fig. 1-4, 8, 11) e na medula. Os canais secretores, associados ao floema, dos ápices caulinares de $S$. dulcis desenvolvem-se da região procambial. As células precursoras do canal secretor mostram sucessivas divisões nos planos periclinais, anticlinais e oblíquos dando origem a células de tamanhos e formas variadas, arranjadas em uma roseta (Fig. 1-2). O lume do canal tem origem a partir do afastamento de algumas células e da degeneração de uma ou mais células desta roseta (Fig. 3). Posteriormente ocorre também a dissolução da lamela média entre as paredes anticlinais das células epiteliais, o que acaba por promover a separação destas (Fig. 4, 8).

Células epiteliais em diferentes estádios do desenvolvimento foram observadas em um mesmo canal secretor, associado ao floema dos ápices vegetativos de Spondias dulcis e de Tapiria guianensis (Fig. 10-11). Algumas células epiteliais observadas eram arredondadas e suas paredes periclinais voltadas para o lume apresentavam contorno sinuoso (Fig. 5, 9). Nas células em estádio senescente, as paredes voltadas para o lume são retas, possuem grandes vacúolos e citoplasma periférico (Fig. 10-11). Geralmente essas células eram mais elétron-densas que as células parenquimáticas subjacentes, devido ao citoplasma rico em organelas, à presença de material osmiofílico e aos inúmeros ribossomos livres (Fig. 5, 8, 11, 13).

Em Tapirira guianensis, as células epiteliais apresentaram vacúolos de vários tamanhos, que continham material elétron-denso (Fig. 11), material floculado elétron-denso (Fig. 15-16), além de gotas elétron-opacas (Fig. 13-14) e restos de membrana (Fig. 14). Estas células, bem como, as dos canais de Spondias dulcis também apresentavam plastídios de formatos variados (Fig. 6-8, 14, 16), mitocôndrias (Fig. 6, 8), dictiossomos (Fig. 8, 15), ribossomos livres (Fig. 6, 15) e retículo endoplasmático rugoso (Fig. 6, 8, 15). Alguns plastídios estavam envolvidos por retículo endoplasmático rugoso, aqui denominado de retículo periplastidial (Fig. 6, 14) e em alguns plastídios de T. guianensis observou-se a presença de pequenas gotas de material elétron-denso (Fig. 14, 16), além da fusão e divisão destes (Fig. 14). Corpos paramurais foram observados no espaço periplasmático das células epiteliais (Fig. 18) e uma bainha de células com material elétron- 


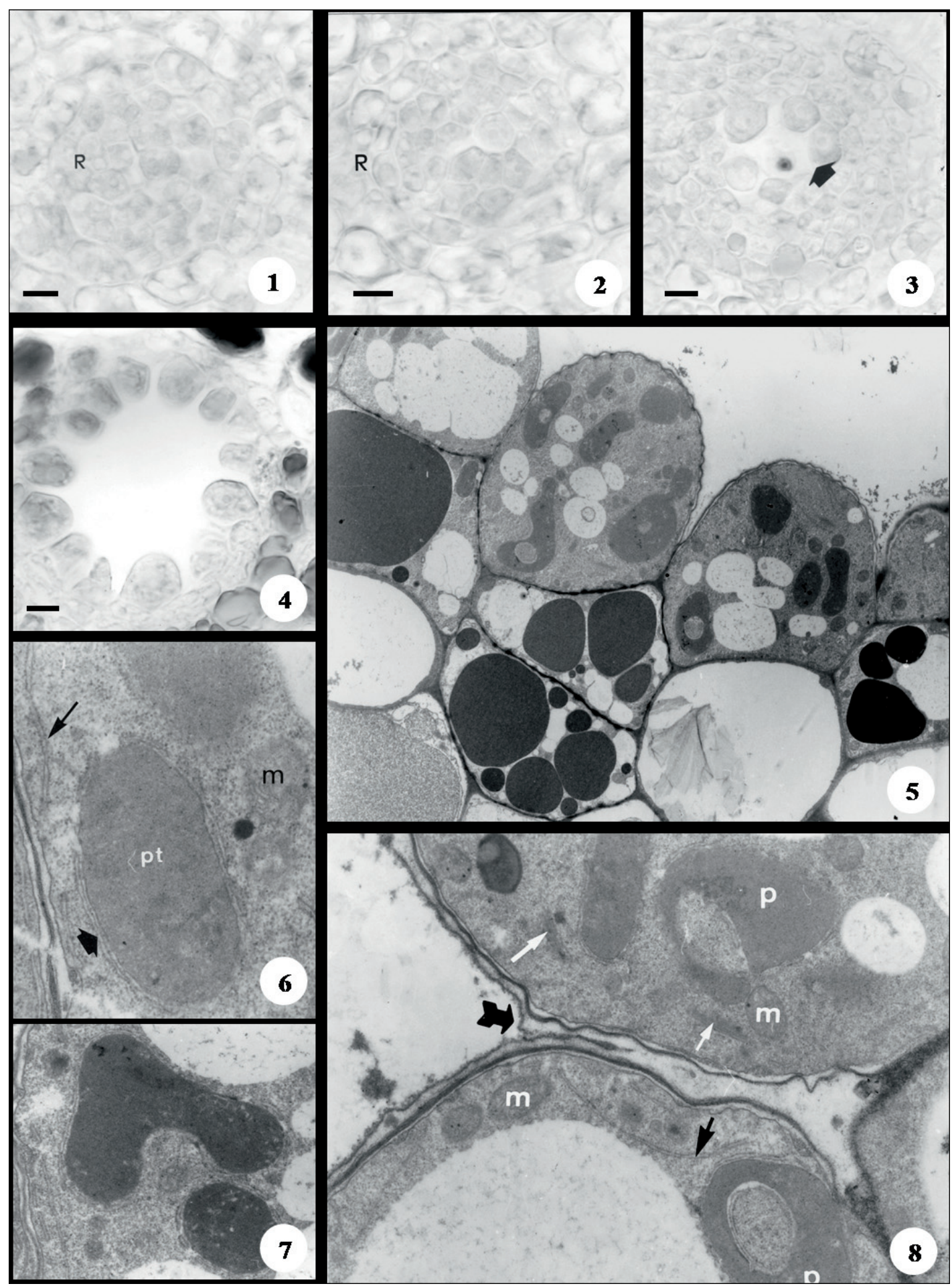

Figuras 1-8. Fotomicrografias (1-4) e elétron-micrografias (5-8) dos canais secretores do floema dos ápices caulinares de Spondias dulcis G. Forst. 1-4. Material fixado em FNT e tratado com preto de Sudão B. 1-2. Canais em formação. 3. Canal em formação com lume e célula central em lise. 4. Canal totalmente formado; células epiteliais afastadas. 5. Canal secretor com células epiteliais de citoplasma denso e organelas (plastídios e vacúolos); bainha do canal composta por idioblastos. 6. Detalhe da célula epitelial; plastídio com retículo periplastidial (seta grossa), RER (seta fina) e mitocôndria (m). 7. Plastídios. 8. Células epiteliais com dissolução da lamela média entre as paredes anticlinais; complexo de Golgi (seta branca), RER (seta preta), plastídios (p) e mitocôndrias (m). Barras = $30 \mu \mathrm{m}$ (1-4); 10 $\mu \mathrm{m}(5) ; 5 \mu \mathrm{m}(6-8)$. 


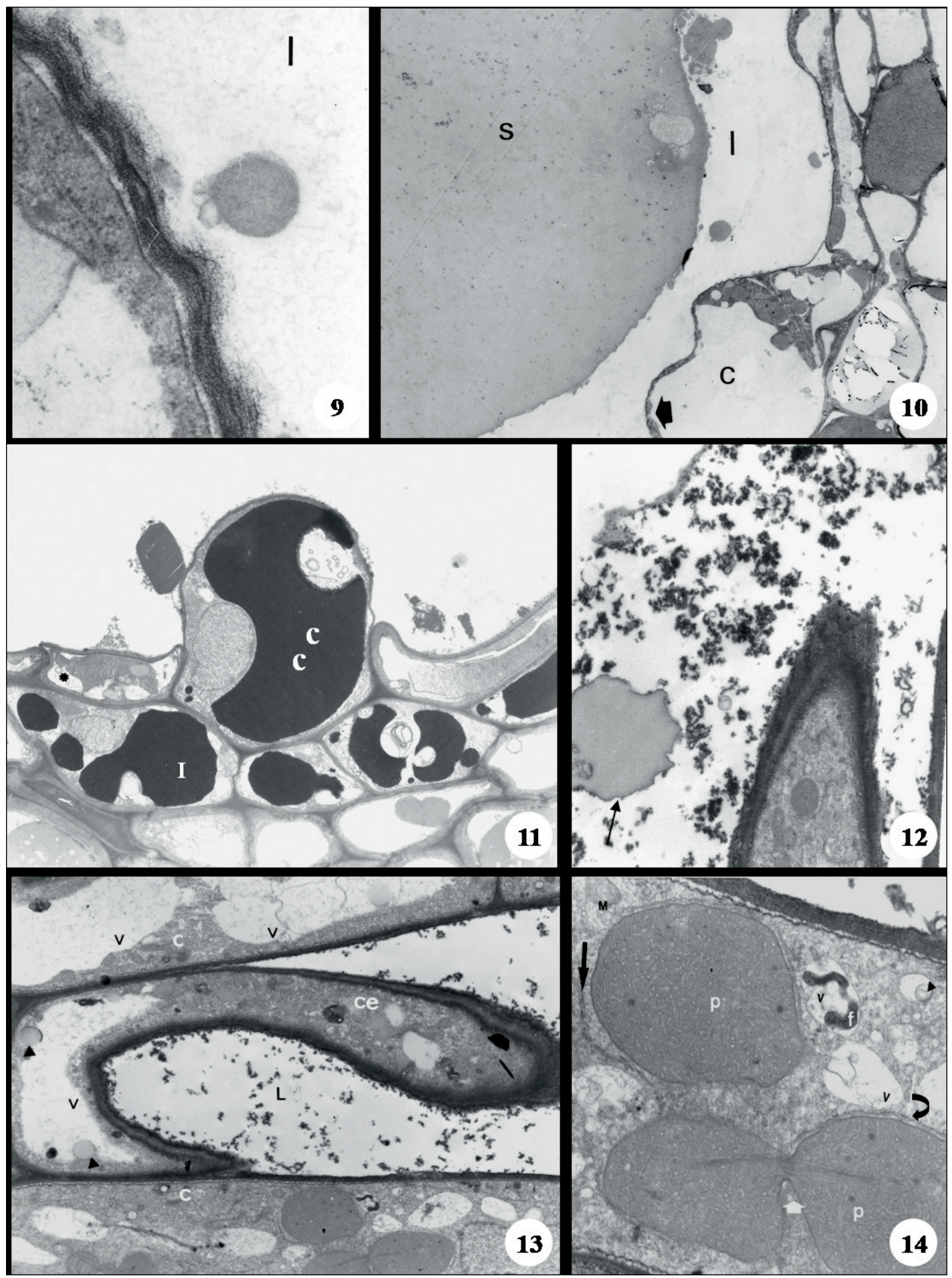

Figuras 9-14. Elétron-micrografias dos canais secretores do floema dos ápices caulinares de Spondias dulcis G. Forst. (9-10) e Tapirira guianensis Aubl. (11-14). 9. Detalhe de uma célula epitelial com parede periclinal externa de contorno sinuoso e gota de material elétronopaca sendo liberada para o lume. 10. Células epiteliais senescentes com citoplasma periférico; lume do ducto com secreção elétron-opaca (5). 11. Células epiteliais (c) em diferentes fases de secreção; bainha de cobertura formada por idioblastos (I). 12. Secreção floculada elétron-densa e homogênea elétron-opaca (seta) no lume do canal. 13. Células epiteliais (c) com vacúolos (v) com gotas elétron-opacas (cabeça de seta); lume (1) com secreção floculada elétron-Densa. 14. Células epitelial com plastídios (p) envoltos por retículo periplastidial (seta curva), RER (seta fina), vacúolos (v) com figuras osmiofílicas (f) e gotas elétron-opacas (cabeça de seta); plastídio com constrição (seta branca). Barras $=2,5 \mu \mathrm{m}(9) ; 5 \mu \mathrm{m}(10-11) ; 2 \mu \mathrm{m}(12-14)$. 
denso pôde ser observada em alguns canais das duas espécies estudadas (Fig. 5, 11). Material elétron-denso foi observado disperso no citoplasma em forma de gotas (Fig. 6,15) ou acumulado na periferia das células epiteliais (Fig. 18). No estádio final da atividade secretora do canal observou-se que as células epiteliais apresentavam um grande vacúolo central como uma fina camada citoplasmática periférica (Fig. 10)

Em Tapirira guianensis a secreção encontrada no lume dos canais, associados ao floema, possuía aspecto heterogêneo (duas fases), com material elétron-opaco de aspecto homogêneo e material elétron-denso floculado (Fig. 12), os canais medulares apresentaram no lume uma quantidade muito maior de secreção (Fig. 17), quando comparados aos canais associados ao floema (Fig. 12). Essa secreção profusa era de material homogêneo elétron denso, elétron opaco e de floculado elétron-denso (Fig. 17). Em Spondias dulcis, a secreção no lume dos canais do floema era elétron-opaca e de aspecto homogêneo.

Flores e frutos - Tapirira guianensis e Anacardium humile - No mesofilo ovariano floral e no mesocarpo do fruto T. guianensis; os canais secretores estão associados ao floema; canais isolados também podem ser observados próximos à epiderme externa ovariana e próximos ao exocarpo, no mesocarpo. Nas flores e nos frutos de Anacardium humile os canais foram observados somente associados ao floema.

Nas flores de Tapirira guianensis, os canais associados ao floema iniciam sua formação a partir da flor em antese e desenvolvem-se nas regiões adjacentes ao procâmbio do mesofilo ovariano. As células precursoras do canal sofrem sucessivas divisões, originando grupos de células dispostas em roseta; no centro da roseta, ocorre a formação de um pequeno espaço intercelular triangular iniciando-se assim o lume (Fig. 19). O lume dos canais é formado como resultado da separação das células centrais por dissolução da lamela média (Fig. 19-20).

No mesofilo ovariano da flor de Tapirira guianensis, a indicação da formação dos canais foi o aparecimento no centro deles, de um espaço resultante da dissolução da lamela média e da progressiva separação das paredes celulares (Fig. 19). Como resultado da dissolução parcial das paredes celulares anticlinais, bem como, da relativa dissolução das paredes periclinais externas (Fig. 20) foram observadas substâncias floculadas elétron-densas no espaço intercelular formado (Fig. 20). As células epiteliais do canal secretor apresentaram, nesta fase, citoplasma elétron-denso (Fig. 19) rico em ribossomos livres (Fig. 21), retículo endoplasmático rugoso (Fig. 20), mitocôndrias (Fig. 20), vacúolos de diverso tamanhos com material floculado elétron-denso (Fig. 19) ou com restos de membrana (Fig. 19, 23), dictiossomos (Fig. 20) e plastídios com estroma elétron-denso (Fig. 22-23). Alguns destes plastídios estavam envolvidos parcial ou totalmente pelo retículo periplastidial (Fig. 22) e, muitas vezes, apresentavam gotas elétron-densas (Fig. 23). Corpos paramurais foram encontrados no espaço periplasmático das células epiteliais (Fig. 23).

Em canais em estádio mais avançado a secreção preenchia todo o lume e podia ser composta somente por material elétron-opaco de aspecto homogêneo (Fig. 24) ou por material elétron-denso floculado, adicionado a material elétron-denso de aspecto homogêneo e a material elétron-opaco de aspecto homogêneo com fino floculado elétron-denso (Fig. 25).

Nos canais do fruto de Tapirira guianensis, observaram-se células epiteliais com grandes vacúolos preenchidos por material elétron-denso (Fig. 26, 28), retículo endoplasmático rugoso, ribossomos livres (Fig. 29) e inúmeros plastídios de diferentes formatos (Fig. 28-29), que podiam estar total ou parcialmente envoltos por retículo endoplasmático rugoso (retículo periplastidial) e apresentavam sistema interno de membranas pouco desenvolvido. Nas células epiteliais também foram observadas inúmeras gotas de material elétron-opaco próximas à parede periclinal externa (Fig. 27-28).

Nas flores de Anacardium humile, os canais, em estádio de desenvolvimento final, apresentaram secreção preenchendo o lume e muitas células epiteliais com citoplasma periférico (Fig. 30). Nos frutos de A. humile pôde-se constatar canais em diferentes fases secretoras; alguns canais possuíam células epiteliais com grande vacúolo central, restringindo o citoplasma à periferia celular (Fig. 31) e outros possuíam células epiteliais com citoplasma denso, rico em vesículas, vacúolos; inúmeros plastídios de forma arredondada com sistema de membranas circular (Fig. 32-33) e gotas elétron-opacas dispersas no citoplasma (Fig. 32). No lume dos canais do fruto de A. humile foi observada secreção de aspecto floculado elétron-denso (Fig. 32).

\section{Discussão}

Nossas observações estruturais e ultra-estruturais revelam que os canais secretores dos ápices vegetativos de Spondias dulcis desenvolvem-se pelo processo esquizolisígeno e que os canais florais de Tapirira guianensis desenvolvem-se pelo processo esquizógeno.

A formação dos canais pelo processo esquizolisígeno e esquizógeno, como constatado para as espécies estudadas, foi anteriormente descrita para outras espécies da família Anacardiaceae. Paula \& Alves (1973), Bhatt \& Mohan Ram (1992) e Machado \& Carmello-Guerreiro 


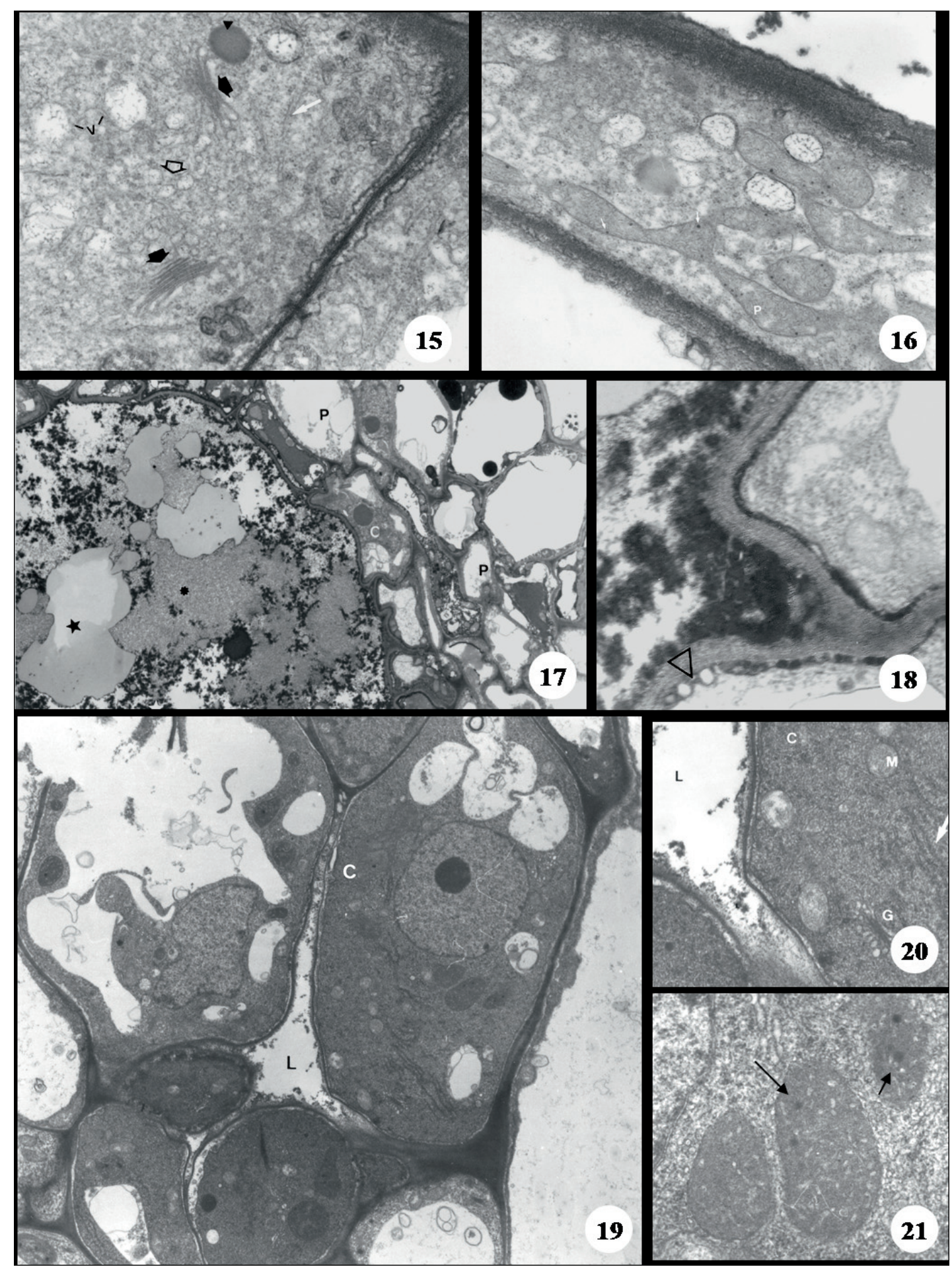

Figuras 15-21. Elétron-micrografias dos canais secretores dos ápices caulinares (15-18) e flores (19-21) de Tapirira guianensis Aubl. 15-16 e 18. Canal do floema. 17. Canal medular. 15. Célula epitelial com vacúolos (v), RER (seta branca), Complexo de Golgi (seta preta cheia), vesículas (seta vazia) e gotas elétron-densas (cabeça de seta). 16. Plastídios de diversos formatos (p) com gotas elétron-densas (seta fina branca). 17. Canal medular com secreção heterogênea composta por material elétron-opaco homogêneo (estrela), elétron-opaco com granulações elétron-densas (asterisco), elétron-denso floculado e elétron-denso homogêneo; células epiteliais de paredes periclinais externas retas (c) e células parenquimáticas subjacentes (p). 18. Detalhe da célula epitelial com corpos paramurais no espaço periplasmático. 19. Canal em início de desenvolvimento com lume (L) reduzido e células epiteliais com citoplasma denso. 20. Célula epitelial (c) com Complexo de Golgi (G), RER (seta) e mitocôndrias (M); material elétron-denso no espaço formado pela separação das paredes periclinais. 21. Plastídios com gotas elétron-densas. Barras = 0,5 $\mu \mathrm{m}(15-16,21) ; 5 \mu \mathrm{m}$ (17); 2,5 $\mu \mathrm{m}$ (18-19); $1 \mu \mathrm{m}$ (20). 


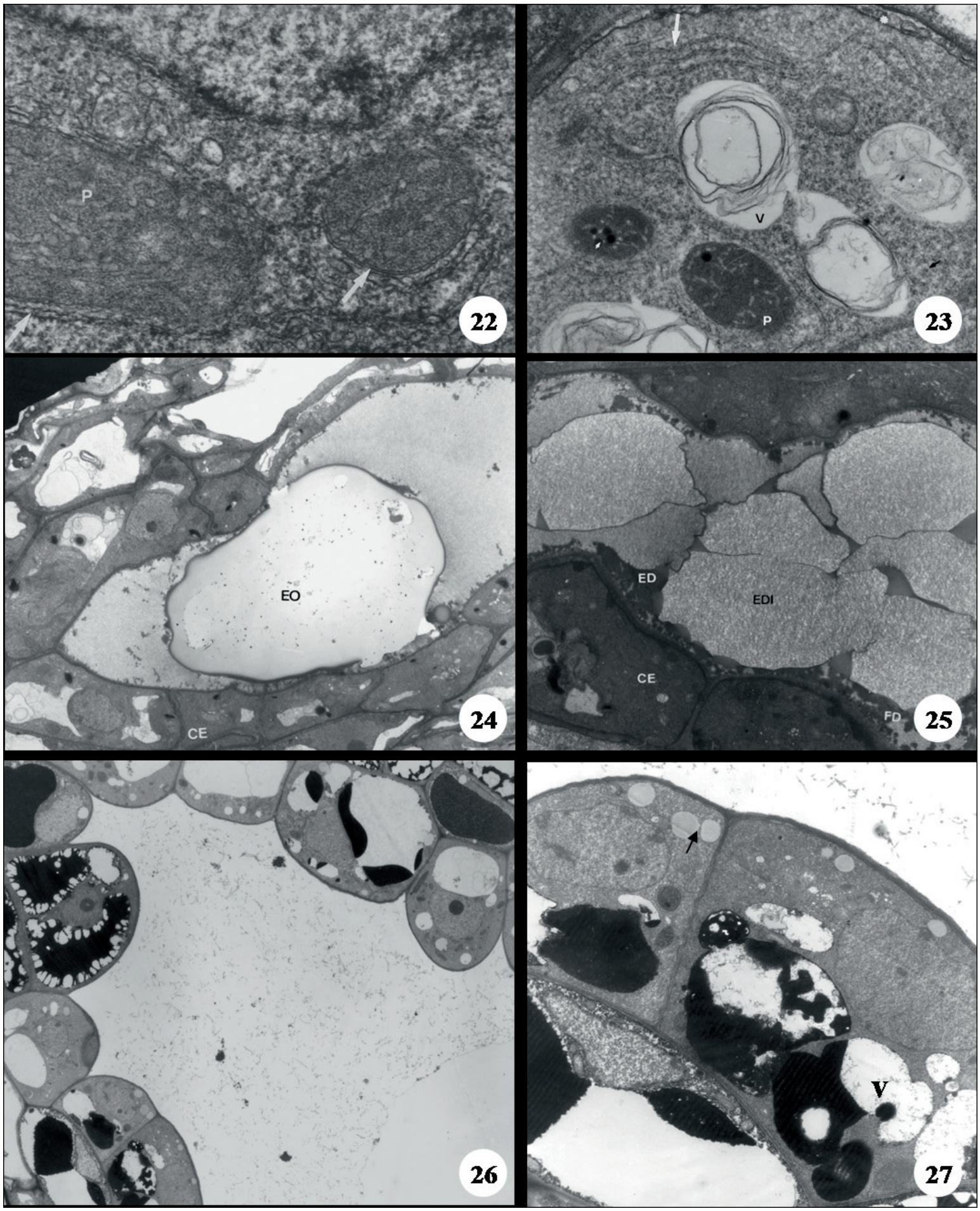

Figuras 22-27. Elétron-micrografias dos canais secretores das flores (22-25) e dos frutos (26-27) de Tapirira guianensis Aubl. 22. Plastídios com retículo periplastidial (seta). 23. Célula epitelial com plastídios (p) com gotas elétron-densas (seta) e vacúolos com restos de membrana. 24. Canal com secreção elétron-opaca (EO) no lume. 25. Canal com secreção heterogênea composta por material elétron-denso homogêneo (ED), elétron-denso opaco com granulações elétron-densas (EDI) e material elétron-denso floculado. 26. Canal com células epiteliais de parede periclinal externa côncava; vacúolos com material elétron-denso. 27. Detalhe da figura 26; célula epitelial com vacúolos de secreção elétron-densa (v), plastídios e gotas elétron-opacas (seta). Barras = $2 \mu \mathrm{m}(22,25) ; 0,5 \mu \mathrm{m}(23) ; 5 \mu \mathrm{m}(24) ; 10 \mu \mathrm{m}(26) ; 2,5 \mu \mathrm{m}(27)$. 


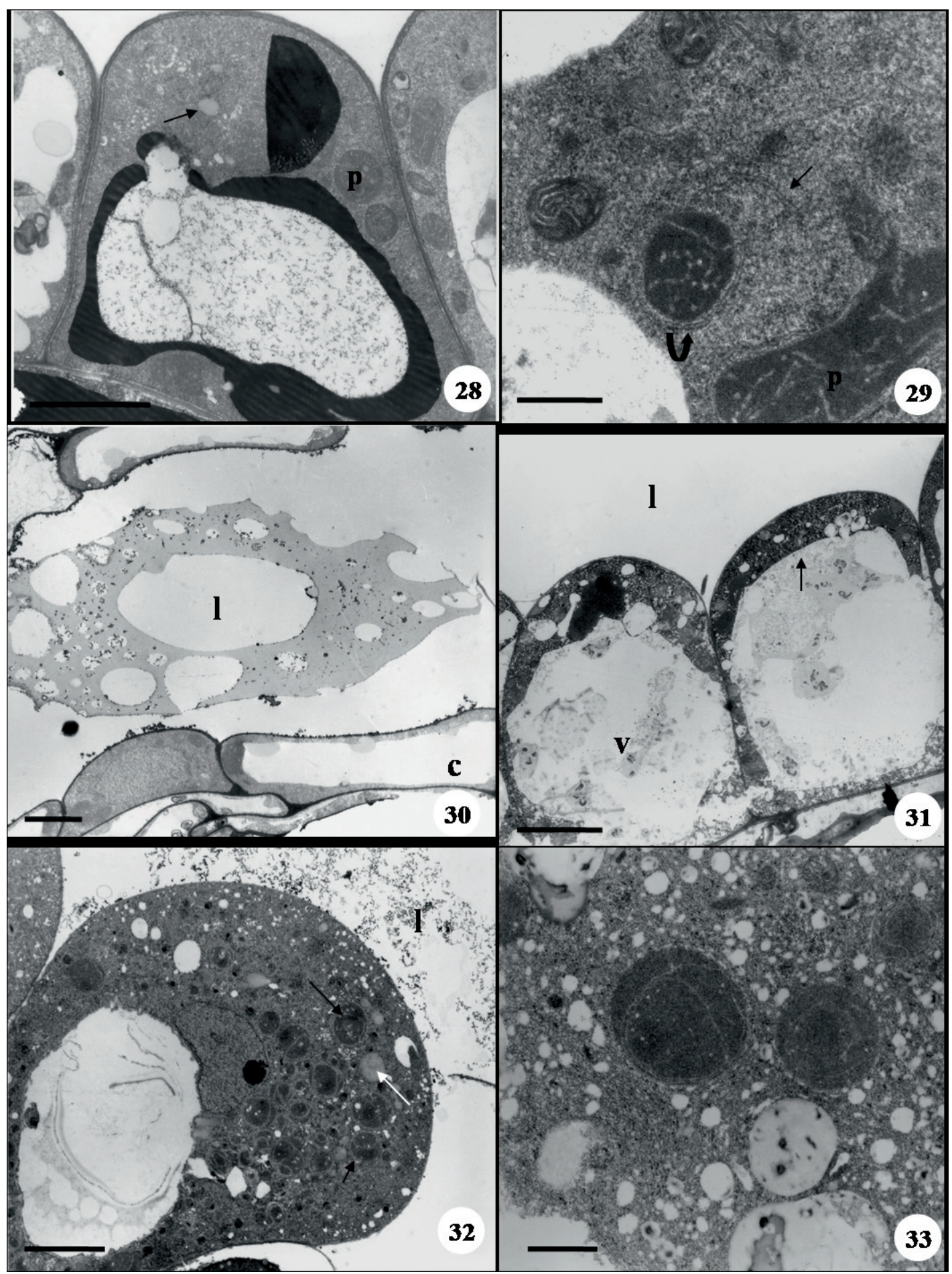

Figuras 28-33. Elétron-micrografias dos canais secretores dos frutos (28-29) de Tapirira guianensis Aubl. e das flores (30) e dos frutos (31-33) de Anacardium humile St.Hil. 28. Célula epitelial com vacúolos de material elétron-denso, plastídios (p) e gotas elétron-opacas. 29. Plastídios (P) com retículo periplastidial (seta curva) e RER (seta fina). 30. Canal secretor com células epiteliais (c) de parede periclinal externa reta e citoplasma periférico; secreção elétron-opaca no lume (1). 31. Células epiteliais de parede periclinal externa côncava, citoplasma periférico e vacúolo central. 32. Célula epitelial com plastídios (seta), vesículas, vacúolos e gotas elétron-opacas (seta branca); secreção elétron-densa floculada no lume (1). 33. Plastídios circulares com membranas internas circulares e vesículas. Barras $=2,5 \mu \mathrm{m}(28,30) ; 0,5 \mu \mathrm{m}(29) ; 5 \mu \mathrm{m}$ $(31,-32), 1 \mu \mathrm{m}(33)$. 
(2001) constataram que em Anacardium, Rhus, Cotinus, Semecarpus anacardium L.f. e Schinus terebinthifolius Raddi o início de formação dos canais é esquizógeno e o desenvolvimento é lisígeno, formando, então, canais tipicamente esquizolisígenos. Outros trabalhos, como os de Mc Nair (1918), Venning (1948), Fahn e Evert (1974) e Nair et al. (1983) relataram o desenvolvimento esquizógeno, em órgãos de algumas espécies de Anacardiaceae, como em Rhus diversiloba, em Schinus, em Rhus glabra e em Anacardium occidentale.

As células ao redor do espaço formado (lume), tanto dos canais dos ápices de Spondias dulcis, que se formam de modo esquizolisígeno, quanto dos canais das flores de Tapirira guianensis, que se formam de modo esquizógeno tornam-se altamente especializadas em secreção, fato comprovado pela microscopia eletrônica de transmissão com a presença de organelas como: RER, ribossomos, mitocôndrias, plastídios e dictiossomos.

Através de testes histoquímicos prévios (A.P.S. Lacchia, dados não publicados) constatou-se que todos os canais estudados possuem como parte da secreção lipofílica óleos essenciais ou resinas, ou ambos, acreditamos que não só os plastídios, mas também outras organelas como RE, mitocôndria e o próprio citosol possam estar envolvidos na produção de uma parte da secreção lipofílica contida nestes canais. A inferência de que outras organelas, além dos plastídios, estão envolvidas na produção de monoterpenos em nossas espécies, está baseada no estudo feito por Turner \& Croteau (2004) que localizaram em tricomas glandulares de Mentha enzimas para a produção de monoterpenos no retículo endoplasmático, na mitocôndria e no citosol

Nas células epiteliais dos canais secretores do ápice caulinar de Spondias dulcis, do ápice, da flor e do fruto de Tapirira guianensis e do fruto de Anacardium humile observou-se plastídios com matriz densa. Em S. dulcis e T. guianensis os plastídios possuem formas variadas, estão parcial ou totalmente envoltos pelo retículo endoplasmático periplastidial e possuem sistema interno de membranas pobremente desenvolvido. Em A. humile, os plastídios são arredondados e apresentam internamente um sistema de membranas disposto de forma circular. A observação de um grande número de plastídios de forma arredondada, em células epiteliais, está sendo pela primeira vez registrada para células epiteliais de membros da família Anacardiaceae.

Nas células epiteliais dos canais secretores florais e do ápice de Tapirira guianensis detectou-se a presença de plastídios com inclusões osmiofílicas, sugerindo que esta organela tenha um papel na atividade secretora de lipídios. Nas células secretoras de substâncias lipofílicas, a característica ultra-estrutural mais comum é a ocorrência de material osmiofílico nos plastídios (Fahn 1988; Duke \& Paul 1993; Sacchetti et al. 1996; Monteiro et al. 1998) o que corrobora nossa sugestão.

Os plastídios encontrados nos canais dos ápices vegetativos de Spondias dulcis possuem sistema de membranas interno pobremente desenvolvido, quando comparados com os plastídios de Tapirira guianensis e com o modelo típico de sistema de membranas interno, bem desenvolvido, proposto por Cheniclet \& Carde (1985). Ainda em relação à produção de monoterpenos, Cheniclet \& Carde (1985) sugeriram que há uma relação entre a estrutura dos plastídios e seus envolvimentos na síntese de monoterpenos. Segundo os autores, quando os óleos essenciais contêm quantidades significativas de monoterpenos, as células secretoras possuem leucoplastos típicos, que segundo estes, são organelas destituídas de ribossomos, de tilacóides e de sistemas internos de membranas desenvolvidos. Ao contrário, quando a fração volátil não contém monoterpenos ou contém apenas uma pequena quantidade, os plastídios mostram várias características estruturais como tilacóides, ribossomos e redes tubulares de membranas bem desenvolvidas.

Desta forma, acredita-se que os plastídios de Spondias dulcis estão muito próximos estruturalmente aos leucoplastos típicos, e assim, apresentam uma quantidade relativamente superior de monoterpenos em relação aos outros constituintes, que podem estar presentes em sua fração lipofílica e em relação à secreção produzida pelos canais de Tapirira guianensis.

Os plastídios encontrados nos frutos de Anacardium humile assemelham-se estruturalmente aos encontrados nos idioblastos oleíferos de Piper, Cannanga e Magnolia por Cheniclet \& Carde (1985); estes plastídios possuem estroma bem denso, membranas lamelares dispostas em círculos, e produzem em seus óleos essenciais pequenas quantidades de monoterpenos hidrocarbonados e uma maior quantidade de sesquiterpenos hidrocarbonados. Assim, infere-se que a secreção lipofílica detectada previamente por histoquímica (A.P.S. Lacchia, dados não publicados), nos canais do fruto de $A$. humile, possui uma pequena fração de monoterpenos quando comparada aos outros constituintes da secreção.

Os plastídios das células epiteliais de Spondias dulcis e de Tapirira guianensis foram encontrados parcialmente ou completamente envolvidos por retículo endoplasmático periplastidial, como em muitas células produtoras de material lipofílico, (Fahn \& Evert 1974; Joel \& Fahn 1980b; Pedro et al. 1991; Bhatt \& Mohan Ram 1992; Carmello et al. 1995; Ascensão et al. 1997; Machado et al. 2006).

Retículo endoplasmático rugoso (RER) e ribossomos livres também foram encontrados nas células epiteliais de Spondias dulcis e Tapirira guianensis. Para Fahn (2000), o retículo endoplasmático participa na síntese de substâncias lipofílicas e pode também auxiliar no trans- 
porte intracelular deste material. O RER, segundo Bhatt \& Mohan Ram (1992) é uma fonte bem conhecida de proteínas e fosfolipídios e para Pridgeon \& Stern (1983) este é o responsável tanto pela síntese como pelo transporte das substâncias nos osmóforos de Restrepia. Bhatt \& Mohan Ram (1992) também sugeriram que o RER poderia estar envolvido no processo de formação da goma-resina dos ductos secretores de Semecarpus anacardium, além dos ribossomos livres revelarem a presença de maquinaria de síntese protéica nas células epiteliais.

Através de testes histoquímicos, substâncias hidrofílicas (polissacarídeos) também foram detectadas na secreção dos canais dos ápices vegetativos de Spondias dulcis e de Tapirira guianensis e dos canais florais e dos frutos de T. guianensis (A.P.S. Lacchia, dados não publicados). Assim como as células epiteliais das espécies estudadas, as células dos canais de Boswellia serrata Roxb. sintetizam e secretam no lume substâncias polissacarídicas em adição as substâncias lipídicas (Nair \& Subrahmanyan 1998).

Muitos tecidos secretores de material lipofílico podem também produzir substâncias adicionais. Os tricomas secretores de Inula viscosa Ait e espécies de Fagonia, por exemplo, secretam polissacarídeos e proteínas em adição ao material lipofílico (Werker \& Fahn 1981; Fahn \& Shimony 1988).

O envolvimento dos dictiossomos na síntese e transporte de polissacarídeos está bem estabelecido em plantas (Fahn 1979; Trachtenberg \& Fahn 1981; Sedgley \& Blesing 1985; Bhatt 1987). Ainda, segundo alguns autores, dictiossomos e vesículas translúcidas podem estar relacionadas à produção dos componentes hidrofílicos da secreção (Figueiredo \& Pais 1992; Jian et al. 1997; Machado et al. 2006), bem como, envolvidos na glicosilacão dos compostos, especialmente alguns componentes tóxicos dos óleos essenciais (Venkaiah 1992; Figueiredo \& Pais 1994).

A importância de organelas, como os dictiossomos, na produção de polissacarídeos também foi observada em ductos gomosos-resiníferos de Mangifera indica (Joel \& Fahn 1980c) e Lannea coromandelica (Venkaiah 1992).

Um modo de formação da goma sugerido por (Nair \& Subrahmanyan 1998), no qual, as substâncias polissacarídicas do lume são resultado da fragmentação parcial da parede tangencial foi observado em algumas espécies, dentre elas, quatro espécies de Anacardiaceae: Rhus glabra, Anacardium occidentale, Semecarpus anacardium e Lannea coromandelica (Fahn \& Evert 1974; Nair et al. 1983; Bhatt \& Mohan Ram 1992; Venkaiah 1992).

Perante o exposto, infere-se que a porção hidrofílica encontrada nos canais de Spondias dulcis e Tapirira guianensis possa ter advindo tanto dos dictiossomos, devido à presença destes e de suas vesículas nas células epiteliais, quanto da degeneração da parede celular tangencial interna, devido sua aparência ondulada e frouxa e à sua fragmentação e desintegração parcial claramente observável nas espécies estudadas.

Corpos paramurais foram observados no espaço periplasmático das células epiteliais dos canais de Tapirira guianensis. Estas estruturas são freqüentemente observadas no estágio inicial de diferenciação dos canais, como visto nos canais da flor de T. guianensis. Os corpos paramurais também foram encontrados em ductos gomosos resiníferos de outras espécies de Anacardiaceae, tais como Anacardium occidentale (Nair et al.1983) e Lannea coromandelica (Venkaiah 1992). Segundo Hall et al. (1984), a abundância de corpos paramurais no citoplasma periférico de células epiteliais pode estar relacionada com processos de dissolução da lamela média, uma vez que, estas estruturas participam da síntese e eliminação de enzimas líticas.

Algumas evidências como a presença de grumos de material elétron-denso dispersos no citoplasma periférico e no espaço citoplasmático sugerem que a eliminação da secreção ocorra por mecanismo écrino (Fahn 1979). Segundo Bhatt \& Mohan Ram (1992), o material osmiofílico em associação com a parede tangencial interna pode passar através do plasmalema por perfusão, diretamente como um resultado da concentração de gradiente, ou mesmo por um processo ativo caracterizando, deste modo, um processo écrino de liberação de resina. Nesta espécie (Bhatt \& Mohan Ram 1992), bem como, em Schinus terebinthifolius (Machado \& Carmello-Guerreiro 2001) os autores relataram a possibilidade de co-existência de padrões écrinos e holócrinos na secreção de resina operando na célula epitelial.

Devido à presença de material osmiofílico em grumos, na periferia das células epiteliais, bem como, a ausência de material secretado em vesículas, infere-se que nos ductos de Tapirira guianensis, Spondias dulcis e Anacardium humile o mecanismo de eliminação da secreção seja preferencialmente écrino.

Os resultados das análises ultra-estruturais das células epiteliais dos canais estudados corroboram com os resultados positivos obtidos pelos testes histoquímicos no lume dos canais, para substâncias hidrofílicas e lipofílicas em Spondia dulcis e Tapirira guianensis e para substâncias lipofílicas em frutos de Anacardium humile (A.P.S. Lacchia, dados não publicados), uma vez que, as células epiteliais de $S$. dulcis e T. guianensis possuem as organelas necessárias (RE, ribossomos, plastídios e dictiossomos) para a produção de substâncias hidrofílicas e lipofílicas e que as células epiteliais do fruto de $A$. humile apresentam plastídios, que são organelas primordiais na secreção de substâncias lipofílicas. A formação dos canais 
por meio de processo esquizolisígeno nos ápices de $S$. dulcis e por meio esquizógeno nas flores de T. guianensis, bem como, as modificações estruturais e ultra-estruturais relacionadas à formação destes canais são condizentes com o modo de formação dos canais de outras espécies da família Anacardiaceae.

Pelos dados ultra-estruturais das células epiteliais dos canais secretores das três espécies estudadas podemos constatar que existem diferenças ultraestruturais em suas células epiteliais, como por exemplo, o tipo de plastídio; embora os canais secretores de Spondias dulcis e Tapirira guianensis produzam secreção de composição semelhante. Um fato novo, em Anacardiaceae, em relação aos aspectos ultra-estruturais dos canais secretores, é a presença de um grande número de plastídios de forma arredondada, nas células epiteliais dos frutos de Anacardium humile. Em relação à formação dos canais, embora tenhamos feito somente o estudo em ápices de $S$. dulcis e em flores de T. guianensis, pudemos verificar, através de registros de formação dos canais em outras espécies de Anacardiaceae, que o tipo de processo de formação dos canais não é um caráter unificador na família, mas um caráter que pode variar enormente entre indivíduos de diferentes espécies e entre órgãos de uma mesma espécie. Um caráter comum observado entre as três espécies estudadas é o modo de liberação da secreção, que para as três espécies estudadas é preferencialmente écrino.

\section{Agradecimentos}

À Fundação de Amparo à Pesquisa do Estado de São Paulo pela Bolsa de Doutorado à primeira Autora (proc. 03/13556-5) e suporte ao projeto temático (Biota/FAPESP proc. 00/12469-3 e 02/13532-6).

\section{Referências bibliográficas}

Angiosperm Phylogeny Group (APG II). 2003. An update of the Angiosperm Phylogeny Group classification for the orders and families of flowering plants: APG II. Botanical Journal of the Linnean Society 141: 399-436.

Ascensão, L.; Marques, N. \& Pais, M.S. 1997. Peltade glandular trichomes of Leonotis leaves; ultrastructure and histochemical characterization of secretions. International Journal of Plant Sciences 158: 249-258.

Bhatt, J.R. 1987. Development and structure of primary secretory ducts in the stem of Commiphora wightii (Burseraceae). Annals of Botany 60: 405-416.

Bhatt, J.R. \& Mohan Ram, H.Y. 1992. Development and ultrastructure of primary secretory ducts in the stem of Semecarpus anacardium (Anacardiaceae). IAWA Bulletin 13: 173-185.

Carmello, S.M.; Machado, S.R. \& Gregório, E.A. 1995. Ultrastructural aspects of the secretory duct development in Lithraea molleoides (Vell.) Engl. (Anacardiaceae). Revista Brasileira de Botânica 18: $95-103$.

Carmello-Guerreiro, S.M. \& Paoli, A.A.S. 2000. Estrutura do pericarpo e da semente de Astronium graveolens Jacq. (Anacardiaceae) com notas taxonômicas. Revista Brasileira de Botânica 23: 87-96. Carmello-Guerreiro, S.M. \& Paoli, A.A.S. 2005. Ontogeny and structure of the pericarp and seed coat of Lithraea molleoides Vell. Engl. (Anacardiaceae) with taxonomic notes. Brazilian Archives of Biology and Technology 48: 599-610.

Cheniclet, C. \& Carde, J.P. 1985. Presence of leucoplasts in secretory cells and of monoterpenes in the essential oil: a correlative study. Israel Journal of Botany 34: 219-238.

Duke, S.O. \& Paul, R.N. 1993. Development and fine structure of the glandular trichomes of Artemisia апnиa L. International Journal of Plant Sciences 154: 107-118.

Fahn, A. 1979. Secretory tissues in plants. London, Academic Press.

Fahn, A. 1988. Secretory tissues in vascular plants. New Phytologist 108: $229-257$.

Fahn, A. 2000. Structure and function of secretory cells. Advances in Botanical Research 31: 37-75.

Fahn, A. \& Evert, R.F. 1974. Ultrastructure of secretory ducts of Rhus glabra L. American Journal of Botany 61: 1-14.

Fahn, A. \& Shimony, C. 1998. Ultrastructure and secretion of secretory cells of two species of Fagonia L. (Zygophyllaceae). Annals of Botany 81: 557-565.

Falcão, W.F.A. 1966. Chave para separar as famílias Anacardiaceae, Burseraceae e Simaroubaceae. Rodriguésia 25: 203-217.

Figueiredo A.C.S. \& Pais M.S. 1992. Ultrastructural aspects of the nectary spur of Limodorum abortivum (L) Sw. (Orchidaceae). Annals of Botany 70: 325-331.

Figueiredo, A.C. \& Pais, M.S. 1994. Ultrastructural aspects of glandular cells from the secretory trichomes and from the cell suspension cultures of Achillea millefolium L. ssp. Millefolium. Annals of Botany 74: 179-190.

Gerlach, D. 1984. Botanische Mikrotechnik: Eine Einführung. $3^{\text {rd }}$ ed. Stuttgart, Georg Thieme

Gibson, A.C. 1981. Vegetative anatomy of Pachycormus (Anacardiaceae). Botanical Journal of the Linnean Society 83: $273-284$

Harada, M. 1937. On the distribution and construction of the resin canal in Rhus succedanea. Botanical Magazine 51: 846-56.

Hall, J.L.; Flowers, T.J. \& Roberts, R.M. 1984. Plant cell structure and metabolism. New York, Longman.

Jian, Z.; Zheng-hai, H. \& Muller, M. 1997. Ultrastructure of the floral nectary of Arabidopsis thaliana L. prepared from high pressure freezing and freeze substitution. Acta Botanica Sinica 39: $289-295$.

Joel, D.M. \& Fahn, A. 1980a. Ultrastructure of resin ducts of Mangifera indica L. (Anacardiaceae). I. Diferentiation and senescence of the shoot ducts. Annals of Botany 46: 225-33.

Joel, D.M. \& Fahn, A. 1980b. Ultrastructure of resin ducts of Mangifera indica L. (Anacardiaceae). II. Resin secretion in the primary stem ducts. Annals of Botany 46: 779-783.

Joel, D.M. \& Fahn, A. 1980c. Ultrastructure of resin ducts of Mangifera indica L. (Anacardiaceae). III. Secretion of proteinpolysaccharide mucilage in fruit. Annals of Botany 46: 785-790.

Johansen, D.A. 1940. Plant Mycrotechnique. New York, McGrawHill Book.

Judd, W.S.; Campbell, C.S.; Kellogg, E.A.; Stevens, P.F. \& Donoghue, M.J. 1999. Plant Systematics. A Phylogenetic Approach. Massachusetts, Sinauer Associates.

Lillie, R.D. 1965. Histopathologic technic and practical histochemistry. $3^{\text {rd }}$ ed. New York, McGraw Hill

Lozano, N.B. 1986. Desarrolo y Anatomia del fruto del jobo (Spondias mobim L.). Caldasia XIV (68-70): 465-490.

Machado, S.R. \& Carmello-Guerreiro, S.M. 2001. Estrutura e desenvolvimento de canais secretores em frutos de Schinus terebinthifolius Raddi (Anacardiaceae). Acta Botanica Brasilica 15: 189-195.

Machado, S.R.; Gregório, E.A. \& Guimarães, E. 2006. Ovary Peltate Trichomes of Zeyheria montana (Bignoniaceae): Developmental 
Ultrastructure and Secretion in Relation to Function. Annals of Botany 97: 357-369.

Mc Nair, J.B. 1918. Secretory canals of Rhus diversiloba. Botanical Gazette 65: 268-273.

Metcalfe, C.R. \& Chalk, L. 1950. Anatomy of the dicotyledons. v.I. Oxford, Clarendon Press.

Monteiro, W.R.; Fahn, A.; Caldeira, W. \& Castro, M.M. 1998. Ultrastructural observations on the foliar secretory cavities of Porophyllum lanceolatum DC. (Asteraceae). Flora 194: 113-126.

Morretes, B.L. 1967. Contribuição ao estudo da anatomia das folhas de plantas do Cerrado II. Boletim da Faculdade de Filosofia, Ciências e Letras da Universidade de São Paulo 305 (Bot. 22): 207-244.

Nair, G.M.; Venkaiah, K. \& Shah, J.J. 1983. Ultrastructure of gumresin ducts in cashew (Anacardium occidentale). Annals of Botany 51: 297-305.

Nair, M.N.B. \& Subrahmanyam, S.V. 1998. Ultrastructure of the epithelial cells and oleo-gum resin secretion in Boswellia serrata (Burseraceae). IAWA Journal 19: 415-427.

Paula, J.E. \& Alves, J.L.H. 1973. Anatomy of Anacardium spruceanum Bth. ex. Engl. (Anacardiaceae) of Amazonia. Acta Amazonica 3: 39-52.

Paula, J.E. \& Heringer, P.E. 1978. Estudo anatômico do fruto Anacardium curatellifolium St. Hil. Com vistas a sua forma e às bolsas oleíferas. Brasil Florestal 9: 33-39.

Pearse, A.G.E. 1985. Histochemistry theoretical and applies. v. 2, C. Livingstone, Edinburg.

Pedro, L.; Campos, P. \& Pais, M.S.S. 1991. Ultrastructure of the apical cell of procumbent (Type I) trichomes in Geranium robertianum L. (Geraniaceae). Israel Journal of Botany 40: 209-217.

Pienaar, M.E. \& Von Teichman, I. 1998. The generic position of Lithraea brasiliensis Marchand (Anacardiaceae) evidence from fruit and seed structure. Botanical Journal of the Linnean Society 126: $327-337$.

Pridgeon, A.M. \& Stern, W.L. 1983. Ultrasctructure of osmophores in Restrepia (Orchidaceae). American Journal of Botany 70: 208-212.

Reynolds, E.S. 1963. The use of lead citrate at high pH as an electronopaque stain in electron microscopy. Journal of Cell Biology 17: 208-212.
Roland, A.M. 1978. General preparations and staining of thin sections. In: J.L. Hall (ed.). Electron Microscopy and Cytochemistry of Plant Cells. New York, Elsevier.

Sacchetti, G.; Bruni, A.; Dall'Olio, G.; Nicoletti, M.; Di Fabio, A. \& Poli, F. 1996. Development and morphology of secretory trichomes of Calceolaria volckmanni (Scrophulariaceae). Nordic Journal of Botany 16: 505-513.

Sedgley, M. \& Blesing, M.A. 1985. Polysaccharide secretion by watermelon stigma. Annals of Botany 55: 269-273.

Trachtenberg, S. \& Fahn, A. 1981. The mucilage cells of Opuntia ficus-indica (L.) Mill. Development, ultrastructure, and mucilage secretion. Botanical Gazette 142: 206-213.

Turner, G.W. \& Croteau, R. 2004. Organization of Monoterpene Biosynthesis in Mentha. Immunocytochemical localizations of Geranyl Disphosphate Synthase, Limonene-6-Hydroxylase, Isopiperitenol Dehydrogenase e Pulegone Reductase. Plant Physiology 136: 4215-4227.

Vassilyev, A.E. 2000. Quantitative ultrastructural data of secretory duct epithelial cells in Rhus toxicodendron. International Journal of Plant Sciences 161: 615-630

Venning, F.D. 1948. The ontogeny of the laticiferous canals in the Anacardiaceae. American Journal of Botany 35: 637-644.

Venkaiah, K. 1992. Development, ultrastructure and secretion of gum ducts in Lannea coromandelica (Hout) Merrill (Anacardiaceae). Annals of Botany 69: 449-457.

Von Teichman, I. 1987. Development and structure of the pericarp of Lannea discolor (Sonder) Engl. (Anacardiaceae). Botanical Journal of the Linnean Society 95: 125-135.

Von Teichman, I. 1998. Micromorphological structure of the fruit and seed of Smodingium argutum (Anacardiaceae), as an adaptation to its natural habitat. South African Journal of Botany 64: 121-127.

Von Teichman, I. \& Van Wyk, A.E. 1991. Taxonomic position of Rhus problematodes (Anacardiaceae): Evidence from fruit and seed structure. South African Journal of Botany 57: 29-33.

Von Teichman, I. \& Van Wyk, A.E. 1994. The generic position of Protorhus namaquensis Sprague (Anacardiaceae) - evidence from fruit structure. Annals of Botany 73: 175-184.

Watson, M.L. 1958. Staining of tissue sections for electron microscopy with heavy metals. Journal of Biophysical and Biochemical Cytology 4: 475.

Werker, E. \& Fahn, A. 1981. Secretory hairs of Inula viscosa (L.) Ait: development, ultrastructure and secretion. Botanical Gazette 142: $461-476$. 